something else in 1961-5 ; this would have had the effect of artificially lowering incidence rates. Conclusively to settle this point is impossible. However, in the initial scanning of the records from which cases were identified all mentions of any kind of intra-abdominal pathology were extracted for examination, and we found no evidence at all of changes in terminology of the kind that would be needed to lower incidence rates.

A second possibility is that sickness absence for duodenal ulcer is becoming shorter. If there were an increase in instances where a doctor with a duodenal ulcer either had an absence of less than a week, or in which he was not away from work at all-perhaps because the condition is becoming milder-a misleading fall in rates might occur. Among the doctors, as for the general population (Morris, 1964), absences for duodenal ulcer tend to be long-presumably mainly for complications. In 1947-50 and 1957-60 the average length of absence for definite duodenal ulcer was 52 days ; in 1961-5 it was 43 days. It is unlikely that this decrease in length of absence could account for the decrease in incidence rates. Moreover, we have shown a trend in the fall of incidence rates between 1947-50, $1957-60$, and 1961-5; there is no corresponding trend in lengths of absence, the figure for the middle period being identical with 1947-50. Further, in $1947-50,8 \%$ of first absences for duodenal ulcer in the doctors were for less than two weeks and in 1957-60 and 1961-5 5\% and 6\% respectively. There is no evidence of a material change in the frequency of short absences.

We conclude that over the last 20 years there has been a true and substantial decline in the incidence of duodenal ulcer among these doctors. Our numbers of new cases and periods of observation are not enough to make possible a cohort study of the kind undertaken for mortality from duodenal ulcer by Susser (1967). Susser's view is that mortality has declined because successive cohorts have carried with them progressively less environmental exposure to factors causing duodenal ulcer. However, mortality is a poor indicator of secular trend in a disease with such a low case fatality. To explain why incidence should be declining involves considering, for example, whether other states may be increasing, thus providing alternative outlets for frustration, tension, anxiety, etc.

We wish to thank the Directors of the Medical Sickness Annuity and Life Assurance Society Limited for permission to examine the records of the Society, and for providing the "populations at risk." We are especially grateful to Dr. T. C. Hunt, Chief Medical Officer, and to Mr. R. G. Barley, General Manager. We are also grateful to Dr. J. A. Heady for his advice.

Requests for reprints should be addressed to Dr. T. W. Meade.

•

REFERENCES

Doll, R., and Hill, A. B. (1964). Brit. med. 7., 1, 1399, 1460.

Hammond, E. C. (1966). Nat. Cancer Inst. Monogr., No. 19, p. 127. Heasman, M. A., and Lipworth, L. (1966). Accuracy of Certification of Cause of Death. General Register Office, Studies on Medical and Population Subjects No. 20. H.M.S.O., London.

Morris, J. N. (1955). Med. Offr, 94, 251.

Morris, J. N. (1964). Uses of Epidemiology, 2nd ed. Edinburgh.

Morris, J. N., Heady, J. A., and Barley, R. G. (1952). Brit. med. 3.,

1, 503. et al. (1963). Circulation, 28, 20.

Paul, O., et al. (1963). Circulation, 28, 20. Amer. med. Ass., 177, 683.

Susser, M. (1967). Y. chron. Dis., 20, 435 .

\title{
Effects of Iron Overload on Ascorbic Acid Metabolism*
}

\author{
A. A. WAPNICK, $\dagger$ M.B., в.CH.; S. R. LYNCH, $\dagger$ м.B., в.CH. ; P. KRAWITZ, $\ddagger$ B.SC. \\ H. C. SEFTEL, $\S$ B.SC., DIP.MED.; R. W. CHARLTON,\| M.D., B.SC., M.R.C.P.ED. \\ T. H. BOTHWELL, M M.D., D.SC., F.R.C.P.
}

Brit. med. F., 1968, 3, 704-707

\begin{abstract}
Cummary : Studies of the ascorbic acid status in two subjects with idiopathic haemochromatosis and in 12 with transfusional siderosis showed that all had decreased levels of white cell ascorbic acid. The urinary excretion of ascorbic acid was also diminished in those subjects in whom such measurements were made. The administration of ascorbic acid was followed by only a small rise in the urinary ascorbic acid output, while the oxalic acid levels (measured in two subjects) showed a significant rise. These findings resemble those described in siderotic Bantu, and support the thesis that increased iron stores lead to irreversible oxidation of some of the available ascorbic acid.
\end{abstract}

\section{Introduction}

Iron overload resulting from prolonged exposure to a high dietary iron intake is extremely common among the Bantu people in Southern Africa (Walker and Arvidsson, 1953; Bothwell and Finch, 1962). The major source of the excessive dietary iron is the home-brewed alcoholic beverages which are consumed in quantity by many adult males (Walker and Arvidsson, 1953 ; Bothwell et al., 1964a). It is consequently this section of the population which shows the highest incidence of severe iron overload (Bothwell and Isaacson, 1962). Scurvy is also common among the Bantu. As in other parts of the world it is seasonal, the highest incidence being at the end of winter and in early spring (Seftel et al., 1966). It is most commonly seen in adult males, and is very rare in children, though other deficiency diseases, such as kwashiorkor, are often encountered (Trowell, 1960).

There is now a considerable amount of evidence indicating that severe iron overload contributes to the development of scurvy in the adult Bantu population. For example, it has been shown that patients presenting with scurvy are invariably heavily siderotic (Bothwell et al., 1964b; Seftel et al., 1966). Moreover, the concentrations of ascorbic acid in the leucocytes of non-scorbutic individuals with no clinical evidence of scurvy

- From the Council for Scientific and Industrial Research, Iron and Red Cell Metabolism Group, Department of Medicine, University of the Witwatersrand Medical School, Johannesburg, South Africa.

t Research Fellow.

S Skilled Technologist.

F Physician.

Physician. Experimental and Clinical Pharmacology, University of the Witwaterstand

Professor of Medicine, University of the Witwaterssand.

This work was supported by a grant (AM04912-07) from the National Institutes of Health, U.S A. 
are much lower than in non-siderotic controls (Lynch et al., 1967a). The probable reason for the association has also been defined. The large storage depots of iron in the body, which are in the ferric form, represent a massive oxidative potential, and it seems probable that a proportion of the available ascorbic acid is irreversibly oxidized by these deposits (Schulz and Swanepoel, 1962). Evidence supporting this thesis has been obtained by administering large amounts of ascorbic acid to siderotic individuals. In such circumstances the auantities of the vitamin voided in the urine remain low, but large amounts of oxalic acid, which is an oxidation product of ascorbic acid, are passed (Lynch et al., 1967b). In addition, the clearance rate of ascorbic acid from the plasma is more rapid in siderotic individuals than in control subjects (Lynch et al., 1967b).

The findings in Bantu with severe siderosis raise the question of whether similar disturbances of ascorbic acid metabolism may not occur in other forms of iron storage disease. Massive iron overload is a feature of the genetic disorder idiopathic haemochromatosis, and has also been noted in certain forms of anaemia. In idiopathic haemochromatosis there is an inappropriate absorption of iron from a normal diet (Charlton and Bothwell, 1967), while multiple factors are involved in the development of the disorder in subjects with anaemia. These include the administration of multiple transfusions to subjects with refractory anaemias, increased absorption from the gut in conditions where there is increased but ineffective erythroid marrow activity, and the injudicious use of iron therapy in subjects with disordered haemoglobin metabolism (Bothwell and Finch, 1962). In the present study certain aspects of ascorbic acid metabolism were investigated in patients with idiopathic haemochromatosis and in subjects with various refractory anaemias.

\section{Subjects Studied}

Twelve patients suffering from anaemias requiring multiple transfusions were investigated. Seven had thalassaemia major, one had sickle-cell thalassaemia, three had aplastic anaemia, and one had myelofibrosis. All had received at least 50 pints (23 litres) of blood before the time of study. Two subjects with idiopathic haemochromatosis who had not previously been venesected were also investigated. The diagnosis was established on the basis of the clinical findings, together with the results of desferrioxamine-induced iron excretion (Lundvall and Weinfeld, 1967) and liver biopsy. Neither of the patients gave a history of exposure to excessive dietary or medicinal iron. Since many of the subjects with transfusional haemosiderosis were children, 10 normal children were included in the 32 subjects who were studied as controls. A full dietary history was obtained from both the siderotic and the control subjects.

\section{Chemical Methods}

White blood cell ascorbic acid concentrations were determined in each patient, and platelet ascorbic acid concentrations were also measured in the majority. (The platelet levels were assessed because it was felt that the apparent white cell values in the thalassaemic patients might not be entirely valid, since some of the subjects had large numbers of erythroid precursors in their peripheral blood.) In addition, urinary ascorbic and oxalic acid determinations were carried out on two subjects with thalassaemia and on two control subjects before and during oral ascorbic acid loading. The basal excretory pattern was established by collecting three 24-hour urine specimens; $250 \mathrm{mg}$. of ascorbic acid was then administered eight-hourly for nine days. During this period the 24-hour urinary excretion of ascorbic acid and oxalic acid was determined each day. The pattern of excretion of ascorbic acid was also studied in the two subjects with idiopathic haemochromatosis before and during ascorbic acid loading.
Urinary ascorbic acid concentrations were measured by the method of Roe (1954). The 24-hour specimens of urine were collected in iron-free vessels containing $100 \mathrm{ml}$. of glacial acetic acid plus edetic acid $(0.5 \mathrm{~g} . / 1$.). The oxalic acid concentrations were determined by the method of Powers and Levatin (1944) except that 100-ml. aliquots of urine were analysed. Leucocyte ascorbic acid was measured as described by Denson and Bowers (1961) ; duplicate estimations showed close agreement (within $10 \%)$. Because of the low leucocyte counts in the two subjects with aplastic anaemia, several samples of blood were pooled before the estimations were performed. The platelet ascorbic acid concentration was determined on $10 \mathrm{ml}$. of blood mixed with $0.5 \mathrm{ml}$. of $10 \%$ edetic acid solution. Erythrocytes and leucocytes were removed by centrifugation at $150 \mathrm{~g}$ for 10 minutes, and the platelets in an aliquot of the supernate were counted. A further aliquot (1-2 ml.) was centrifuged at 1,600 $g$ for 30 minutes; the supernatant was then discarded and the deposit washed with $10 \mathrm{ml}$. of $0.9 \% \mathrm{NaCl}$ solution. A volume of $1.3 \mathrm{ml}$. of $5 \%$ trichloracetic acid was added to the deposit and the ascorbic acid content was determined in the same way as for leucocytes.

The platelet ascorisic acid technique was validated by comparing the ascorbic acid concentrations in leucocytes and platelets in 35 subjects. In order to obtain a range of concentrations for comparison, 13 scorbutic individuals were included. The correlation was good $(r=+0.847, P<0.001$ ) (Fig. 1). The mean platelet ascorbic acid concentration in the non-seorbutic individuals was $81 \mu \mathrm{g} . / 10^{10}$ platelets (range $51-143 \mu \mathrm{g}$ ).

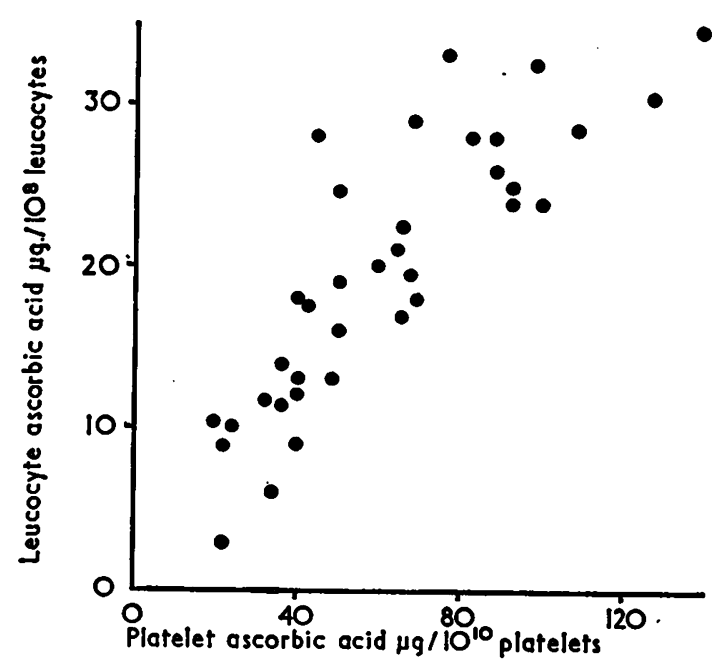

FIG. 1.-Correlation between leucocyte and platelet ascorbic acid concentrations $(r=+0.847, \mathrm{P}<0.001)$.

\section{Results}

The dietary histories of both the siderotic and the control subjects were unremarkable. They consumed normal amounts of milk, fresh fruit, and vegetables, and the alcoholic intake of the adult subjects was low. None of the siderotic individuals showed any clinical evidence of scurvy. Both the leucocyte and platelet ascorbic acid concentrations in the siderotic subjects were lower than in any of the normal control individuals (Table I). The mean leucocyte ascorbic acid concentration in normal adults was $30.2 \mu \mathrm{g} . / 10^{8}$ leucocytes, and the lowest figure was $20.3 \mu \mathrm{g} . / 10^{8}$ leucocytes. The figures in the normal children were very similar, the mean being $29.9 \mu \mathrm{g}$. ascorbic acid per $10^{8}$ leucocytes, with the lowest figure $22.5 \mu \mathrm{g} .110^{8}$ leucocytes. In contrast, the highest figure in the siderotic subjects was $19.7 \mu \mathrm{g} . / 10^{8}$ leucocytes, while the mean figure was only $9.0 \mu \mathrm{g} . / 10^{8}$ leucocytes. The platelet ascorbic acid concentrations in the siderotic individuals were also low, which indicates that the low leucocyte concentrations were not due 
simply to dilution of the leucocytes by normoblasts in the Buffy layer. The mean platelet ascorbic acid concentration in the siderotic group was $26.0 \mu \mathrm{g} . / 10^{10}$ platelets, compared with a mean figure of $81 \mu \mathrm{g} . / 10^{10}$ platelets in 22 normal subjects.

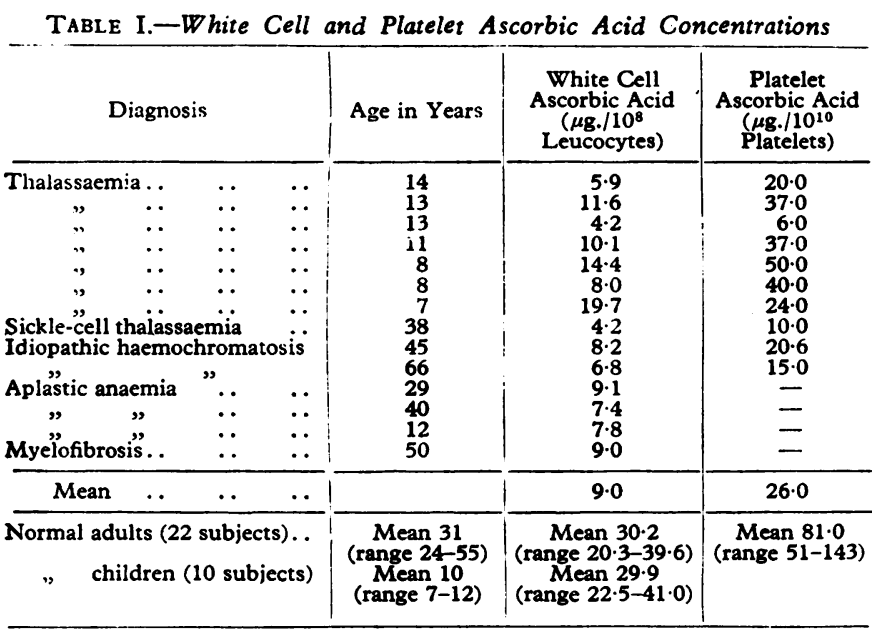

White cell ascorbic acid concentrations were repeated on three of the siderotic subjects at intervals after they had been "saturated" with $250 \mathrm{mg}$. of ascorbic acid three times daily for seven days. Within two months the levels had returned to approximately the same low figures as previously (Table II).

TABLE II.-Follow-up Levels of Ascorbic Acid in Three Siderotic Subjects After Administration of Ascorbic Acid (750 mg. daily) for Seven Days

\begin{tabular}{|c|c|c|c|}
\hline \multicolumn{4}{|c|}{ White Cell Ascorbic Acid Concentrations ( $\mu \mathrm{g} \cdot / 10^{8}$ Leucocytes) } \\
\hline \multirow{2}{*}{$\begin{array}{l}\text { Values before } \\
\text { Ascorbic Acid } \\
\text { Administration }\end{array}$} & \multicolumn{3}{|c|}{ Subsequent Levels } \\
\hline & $\begin{array}{l}\text { After One Week } \\
\text { on Ascorbic Acid }\end{array}$ & $\begin{array}{c}\text { One Month } \\
\text { Later }\end{array}$ & $\begin{array}{c}\text { Two Months } \\
\text { Later }\end{array}$ \\
\hline $\begin{array}{l}7 \cdot 1 \\
8 \cdot 9 \\
4 \cdot 1\end{array}$ & $\begin{array}{l}43.9 \\
44.5 \\
38.9\end{array}$ & $\begin{array}{l}20 \cdot 3 \\
23 \cdot 5 \\
23 \cdot 4\end{array}$ & $\begin{array}{r}11.6 \\
9.6 \\
8.7\end{array}$ \\
\hline
\end{tabular}

The basal excretion of ascorbic acid was measured in two thalassaemic subjects, in two subjects with idiopathic haemochromatosis, and in two normal control individuals. It was lower than normal in the siderotic individuals (Fig. 2). The oral administration of ascorbic acid was followed by the appearance of considerable amounts of ascorbic acid in the urine

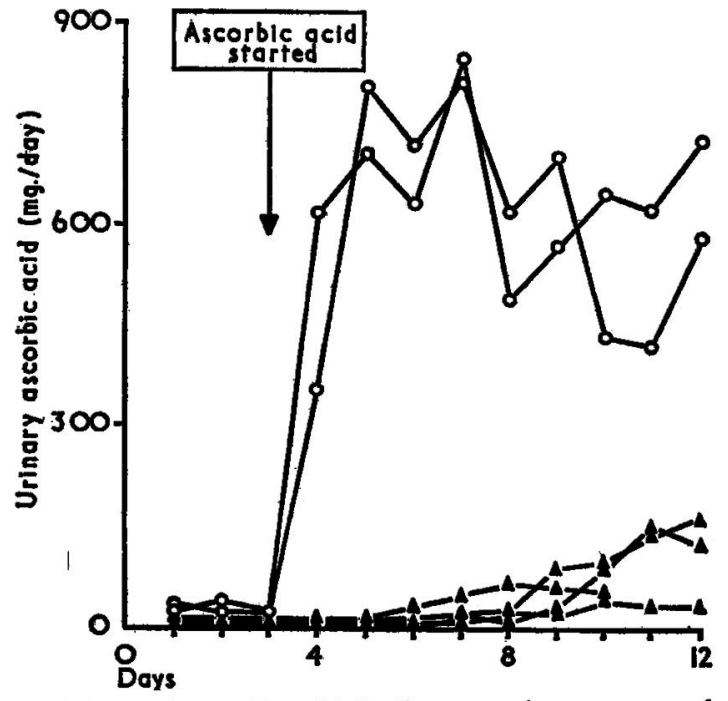

FIG. 2.-Effects of ascorbic acid loading on urinary output of ascorbic acid in four patients with iron overload (closed triangles) and in two normal subjects (open circles). of the control subjects, with virtually the entire daily dose appearing in the 24-hour urine after three days. The increase in urinary ascorbic acid excretion was much less marked in the siderotic individuals, and even after nine days only $20 \%$ at most of the administered dose was recovered in the urine.

There was little difference in the basal urinary oxalic acid content of two control subjects and two individuals with thalassaemia major (Fig. 3). The oral administration of ascorbic acid did not affect the urinary oxalic acid excretion of the normal subjects, but an increase occurred after several days in the thalassaemic individuals.

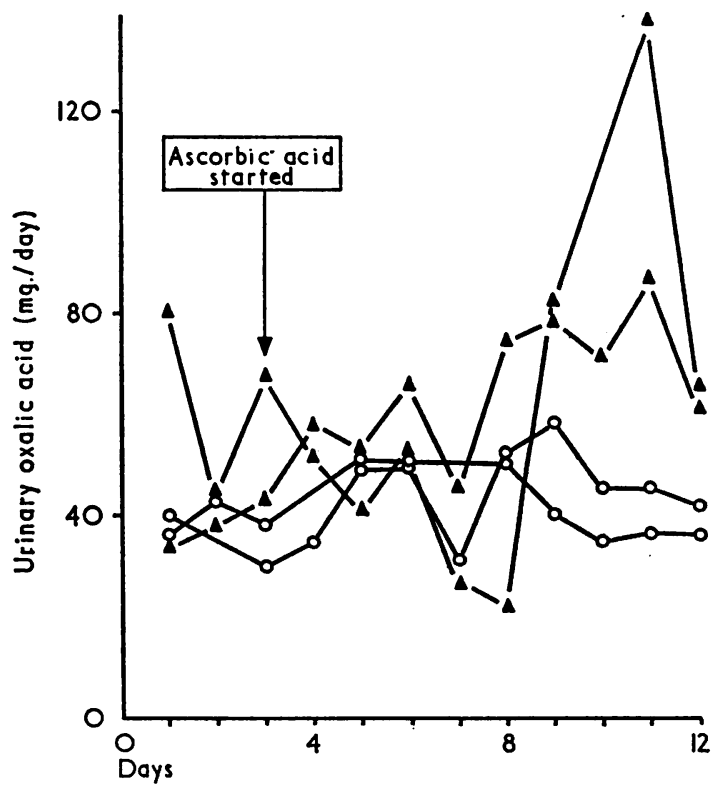

FIG. 3.-Effects of ascorbic acid loading on urinary output of oxalic acid in two siderotic patients with thalassaemia major (closed triangles) and in two normal subjects (open circles).

\section{Discussion}

The present investigation has established that subjects with idiopathic haemochromatosis and with transfusional siderosis exhibit the same type of abnormal ascorbic acid metabolism as do severely siderotic South African Bantu subjects. Leucocyte and platelet ascorbic acid concentrations were found to be consistently lower than normal, and the oral administration of ascorbic acid resulted in only a slight increase in the urinary ascorbic acid excretion compared with control subjects. In addition, the administration of ascorbic acid to two patients with thalassaemia led to an increased excretion of the oxidation product, oxalic acid, in the urine. These various findings, when taken together, suggest that iron overload of several different types can lead to the irreversible oxidation of a proportion of the available ascorbic acid. At the same time it is apparent that the deviations from normal are not as severe as those previously noted in severely siderotic Bantu (Lynch et al., 1967a). The leucocyte ascorbic acid concentrations were not as low, and none showed clinical evidence of scurvy. This can almost certainly be ascribed to the good diet consumed by all these subjects. In contrast, the dietary ascorbic acid intake in most heavily siderotic Bantu subjects is low, and in late winter and early spring it is even lower than at other times of the year. This is the season when clinical scurvy is most commonly seen in these subjects (Seftel et al., 1966). It is therefore probable that irreversible oxidative catabolism of ascorbic acid by the ferric iron deposits in these individuals is only partly responsible for the development of scurvy, and that dietary deficiency is a contributing factor.

The present findings may possibly have a wider relevance. Among the Bantu severe siderosis and ascorbic acid deficiency 
have been shown to be associated with an unusual variety of osteoporosis (Grusin and Samuel, 1957; Seftel et al., 1966 ; Lynch et al., 1967a). This osteoporosis occurs in middle-aged manual labourers, and commonly presents with vertebral body collapse. Some affected individuals exhibit clinical scurvy, but in others the ascorbic acid deficiency has been manifested only by decreased leucocyte ascorbic acid concentrations. It has been suggested, though not proved, that the severe siderosis contributes to the development of the ascorbic acid deficiency, which in its turn leads to diminished bone formation. While this may prove not to be the correct explanation there is no doubt that a close clinical association exists in the Bantu between severe siderosis, ascorbic acid deficiency, and osteoporosis. In this context it may be noteworthy that osteoporosis has been found in white subjects with haemochromatosis (Delbarre, 1960). In addition, it is possible that the skeletal changes noted in thalassaemia (Caffey, 1957) may not be the result only of an expanded bone marrow. The subject is therefore one which warrants further study.
REFERENCES

Bothwell, T. H., and Finch, C. A. (1962). Iron Metabolism. Boston.

Bothwell, T. H., and Isaacson, C. (1962). Brit. med. F., 1, 522.

Bothwcll, T. H., Seftel, H., Jacobs, P., Torrance, J. D., and Baumslag, N. (1964a). Amer. F. clin. Nutr., 14, 47.

Bothwell, T. H., et al. (1964b). Brit. F. Haemat., 10, 50.

Caffey, J. (1957). Amer. F. Roentgenol., 78, 381.

Charlton, R. W., and Bothwell, T. H. (1967). In Progress in Hematology, vol. 5, p. 298, edited by E. B. Brown and C. V. Moore. London.

Delbarre, F. (1960). Sem. Hôp. Paris, 36, 3279.

Denson, K. W., and Bowers, E. F. (1961). Clin. Sci., 21, 157.

Grusin, H., and Samuel, E. (1957). Amer. F. clin. Nutr., 5, 644.

Lundvall, O, and Weinfeld, A. (1967), 7. clin. Path., 20, 611.

Lynch, S. R., et al. (1967a). Amer. F. clin. Nutr., 20, 799.

Lynch, S. R., Seftel, H. C., Torrance, J. D., Charlton, R. W., and Bothwell, T. H. (1967b). Amer. F. clin. Nutr., 20, 641.

Powers, H. H., and Levatin, P. (1944). F. biol. Chem., 154, 207.

Roe, J. H. (1954). Meth. biochem. Anal., 1, 134.

Schulz, E. J., and Swanepoel, H. (1962). S. Afr. med. F., 36, 367.

Seftel, H. C., et al. (1966). Brit. med. J., 1, 642.

Trowell, H. C. (1960). Non-Infective Disease in Africa, p. 363. London.

Walker, A. R. P. and Arvidsson, U. B. (1953). Trans, roy. Soc. trop. Med. Hyg., 47, 536 .

\title{
Relation between Airways Obstruction and $\mathrm{CO}_{2}$ Tension in Chronic Obstructive Airways Disease
}

\author{
D. J. LANE,*§ M.A., B.M., M.R.C.P. ; J. B. L. HOWELL, † PH.D., B.SC., F.R.C.P. ; B. GIBLIN $\ddagger$
}

Brit. med.7., 1968, 3, 707-70)

\begin{abstract}
Ummary : The relationship between the F.E.V..$_{1}$ as an $\sim$ index of airways obstruction and $\mathrm{PcO}_{2}$ as an index of hypoventilation was investigated in 13 patients with chronic obstructive airways disease. Patients who had a normal $\mathrm{PCO}_{2}$ despite severe airways obstruction retained relatively normal sensitivity to $\mathrm{CO}_{2}$ as assessed by their "inspiratory mechanical work rate" response to $\mathrm{CO}_{2}$. Others showed a raised $\mathrm{Pco}_{2}$ in the presence of lesser degrees of airways obstruction and had reduced sensitivity to $\mathrm{CO}_{2}$.
\end{abstract}

\section{Introduction}

While hypoventilation in obstructive airways disease is generally considered to be proportional to the degree of airways obstruction (Baldwin et al., 1949) a number of exceptions have been reported. McNicol and Pride (1965) described four cases of " unexplained underventilation of the lungs" in the presence of only mild airways obstruction; the one-second forced expiratory volume (F.E.V..$_{1}$ ) in these subjects was $1.30-1.451$., while the arterial carbon dioxide tension $\left(\mathrm{PCO}_{2}\right)$ ranged from 55 to $83 \mathrm{~mm}$. Hg. By contrast Tai and Read (1967) reported blood gas studies in acute bronchial asthma, where, despite severe airways obstruction-for example, F.E.V. 0.5 1.-hypoventilation, as measured by a raised $\mathrm{PCO}_{2}$, was uncommon. This apparent discrepancy is not confined to these two situations; even among patients with chronic airways obstruction associated with chronic bronchitis and emphysema the $\mathrm{PCO}_{2}$ does not necessarily rise with increasingly severe airways obstruction. Those cases described by Fletcher et al. (1963) as "emphysematous" tend to have a lower $\mathrm{PCO}_{2}$ than those described as "bronchitic" at similar values of F.E.V... These

* Research Registrar.

t Consultant Physician and Senior Lecturer.

$¥$ Research Technician.

University Department of Medicine, Manchester Royal Infirmary.

$\$$ Present address: Nuffield Department of Clinical Medicine, the Radcliffe Infirmary, Oxford differences between patients indicate that the level of $\mathrm{PCO}_{2}$ is influenced by a factor or factors other than the degree of airways obstruction.

This report concerns a further examination of the relation between F.E.V..$_{1}$ and $\mathrm{PCO}_{2}$ in a group of patients with chronic obstructive airways disease and follows up an earlier suggestion (Howell, 1966) of some correlation between the F.E.V. $._{1} / \mathrm{PCO}_{2}$ relationship and $C_{2}$, sensitivity.

\section{Patients and Methods}

The 13 patients included in this study were attending the outpatient department regularly for follow-up of chronic airways obstruction associated with chronic bronchitis, emphysema, or allergic airways disease (Howell and Altounyan, 1967). They were selected because sufficient measurements of F.E.V..$_{1}$ and $\mathrm{PCO}_{2}$ had been made at different times to construct plots such as those shown in Fig. 2.

Spirometry was performed on a Godart Pulmonet, and resting $\mathrm{PCO}_{2}$ was estimated by the rebreathing method of Campbell and Howell (1962). Dynamic response to $\mathrm{CO}_{2}$ was measured during rebreathing from a 4-litre bag of $100 \%$ oxygen. Endtidal $\mathrm{PCO}_{2}$ was measured with an infrared analyser (Infra Red Development Company, Model DVB). Minute-ventilation and tidal volumes were measured with a Godart pneumotachograph with integrator, and pressure recordings from an intraoesophageal balloon sited in the lower third of the oesophagus were made by means of an N.E.P. capacitance manometer. Simultaneous volume and pressure signals were fed into an $\mathrm{XY}$ recorder (Bryans Model 20171), where pressure/volume loops were traced out for individual breaths. The dynamic compliance line for the lungs and the compliance line for the chest wall (calculated from a previously determined total compliance) were drawn in. From this plot the area representing work done during inspiration against viscous and elastic resistances in the lungs was measured by planimetry. Figures for work done per breath were converted to a work rate ("inspiratory 